\title{
APPLICATION OF SILANE COUPLING AGENTS TO ABACA FIBERS FOR
}

\section{HYDROPHOBIC MODIFICATION}

\author{
BRENT SPENCER C. SIY, JOHN ALFRED XAVIER C. TAN, ${ }^{*}$ KIMBERLY P. VIRON, ${ }^{*}$ \\ NORMIE JEAN B. SAJOR, ${ }^{* *}$ GIL NONATO C. SANTOS ${ }^{* *}$ and DAVID P. PENALOZA JR. \\ ${ }^{*}$ Chemistry Department, College of Science, De La Salle University, Manila 0922, Philippines \\ ${ }^{* *}$ Physics Department, College of Science, De La Salle University, Manila 0922, Philippines \\ $\bowtie$ Corresponding author: D. P.Penaloza Jr., david.penaloza.jr@dlsu.edu.ph
}

Received November 8, 2019

In this study, two organotrialkoxysilane coupling agents: 3-(trimethoxysilyl) propyl methacrylate (TMPS) and octyl triethoxy silane (OTES), were employed for hydrophobic modification of abaca fibers. This approach was deemed to address the inherent hydrophilicity of abaca fibers, which limits their ability to serve as filler for polymer composites. Hydrophobized abaca fibers can discourage high moisture absorption, which usually causes poor fiber dispersion and fiber-matrix interfacial adhesion in fiber reinforced polymer composites. Fourier-transform infrared (FTIR) spectroscopic measurements and significantly higher contact angles exhibited by the fibers modified with these silane agents, compared to those of untreated abaca, verified the successful hydrophobic modification of the fiber materials.

Keywords: abaca fibers, composite, chemical modification

\section{INTRODUCTION}

The utilization of natural fibers as reinforcement for various resins, in lieu of synthetic fiber materials, for polymer-based composite preparation has received a lot of attention due to their low cost, natural abundance, renewability, eco-friendliness, remarkable specific strength and low density. ${ }^{1-7}$ Also, processing these materials, unlike conventional fibers, does not result in any harmful gases and is not abrasive to the processing equipment. Furthermore, in considering natural fibers for composites, a balance between sustainability and product performance can be achieved. Commercially, natural fiber composites are used in the manufacture of different parts of automotives, boats, sporting equipment and in many other commodities.

One particular natural fiber of interest is that of abaca (Musa textilis), which is endemic to the Philippines. ${ }^{8-10}$ Abaca fiber morphologically resembles that of a banana plant, with 12-30 stalks stemming from a central root system, giving a shrubby appearance and a false trunk. Each of the stalks can grow up to 4-8 $\mathrm{m}$ and these are mechanically stripped, tuxied or decorticated to produce the abaca fiber. ${ }^{11}$ The fiber is made up of around 66\% cellulose, $25 \%$ hemicelluloses, $14 \%$ lignin and 0.7 water. $^{12}$ Its remarkable mechanical properties are related to three microstructural features: a high Runkel ratio, meaning a high cell wall volume to lumen width (empty cavity within the fiber) proportion; ${ }^{13}$ high cellulose content, compared to that of hemicelluloses and lignin; ${ }^{11}$ and a microfibril angle with orientation close to the fiber bundle. ${ }^{14}$ A particular case in point highlighting the commercial value of this fiber as a composite additive material is when A. G. Daimler successfully developed and patented a polypropylene composite reinforced by abaca fibers to be used as under-floor components and covering of spare tire wheels of a Mercedes-Benz A-Class passenger car, meeting rigorous quality requirements for road transportation. ${ }^{15-17}$

What limits the maximum utilization of natural fibers, such as abaca, as promising alternatives to traditional resin reinforcement materials is their inherent hydrophilic nature. The high hydrophilicity of natural fibers can lead to high moisture absorption and, when they are used as fillers in composite materials, results in poor fiber dispersion and fiber-matrix interfacial 
adhesion. $^{18-23}$ To address these issues, fiber surface modification is considered.

This study focuses on the surface modification of abaca fibers using two kinds of organotrialkoxysilane coupling agents: 3(trimethoxysilyl) propyl methacrylate (TMPS), and octyl triethoxy silane (OTES) (Fig. 1). To verify the successful modification of the abaca fibers, Fourier transform infrared (FTIR) spectroscopic measurements of the modified abaca fibers (using different silane agents) and unmodified abaca (as control) were conducted. FTIR spectroscopy is a good characterization tool to use in determining the functional groups present in a sample. ${ }^{24-26}$ The wetting behavior of the modified and unmodified fibers was characterized through contact angle (CA) analysis.

\section{EXPERIMENTAL}

\section{Materials}

Abaca fibers were obtained from the Department of Science and Technology of the Philippine Textile Research Institute (PTRI-DOST). Two types of organotrialkoxysilane coupling agents were used as received: 3-(trimethoxysilyl) propyl methacrylate (TMPS) and octyl triethoxy silane (OTES).

\section{Preparation of organosilane solutions as a dip bath}

To prepare the organotrialkoxysilane dipping solution, the solvent consisted of ethanol:water in a $4: 1$ mole ratio. An appropriate amount of silane coupling agent was then added to prepare a 1:10 mole ratio (silane:solvent). The mixture was then stirred at a constant rate for 2 hours and the $\mathrm{pH}$ was adjusted to 4.00 using acetic acid. This is a modified method reported by Mendes et al. ${ }^{27}$

\section{Immersion of fibers in organosilane solutions}

Abaca fiber samples (0.50 g) were dipped in the organotrialkoxysilane solution for 3 hours, then taken out of the solution and allowed to stand on a surface at room temperature. Then, they were washed with an ethanol/water mixture to remove excess silane and, finally, were oven dried prior to characterization.

\section{Characterization of silane-modified and unmodified abaca fibers}

The organo-modified fibers were analyzed using Fourier-transform infrared (FTIR) spectroscopy to verify the success of the modification of the fiber materials. Also, contact angle (CA) analysis was performed to characterize their surface properties in comparison with those of unmodified abaca fiber.

\section{Fourier-transform infrared (FTIR) spectroscopy}

This technique was utilized to monitor the modification of the abaca fiber after the reaction with various silane coupling agents. The FTIR spectra of the samples were obtained on a Thermo Scientific Class 1 Nicolet 6700 FTIR spectrometer, in the range of 400$4000 \mathrm{~cm}^{-1}$, with 16 scans performed. Each of the tested samples was ground, added to $\mathrm{KBr}$ and then pelletized prior to FTIR analysis.

\section{Contact angle (CA) analysis}

Abaca fibers were compressed into a pellet ringlike structure. Each sample was placed on the holder platform of the contact angle setup. Using a micropipette, $5 \mu \mathrm{L}$ of distilled water was applied onto five random locations on the fiber surface. The static water contact angle of each sample was determined from the capture photo of the droplet, using a Theta Lite Optical Tensiometer TL-100, controlled with OneAttension software, capable of determining the contact angle of a water droplet calculated from the live image with advanced machine vision capability.

\section{RESULTS AND DISCUSSION \\ Surface modification of abaca fibers using silane coupling agents \\ Silane coupling agents are often utilized in the} preparation of composite materials as modifying agents for the filler component through the introduction of functional groups or long, nonpolar carbon structures. They have a general structure: $(\mathrm{RO})_{3}-\mathrm{Si}-\mathrm{R}^{\prime}-\mathrm{X}$, where $\mathrm{X}$ is an organofunctional group, $\mathrm{R}^{\prime}$ is a carbon linkage, and RO is a hydrolyzable group, like an alkoxy group. $^{28-29}$ Figure 1 shows the structure of the organotrialkoxysilane coupling agents used in the abaca fiber modification.

After silane modification of the abaca fibers, the samples were subjected to FTIR spectroscopic analyses. Figure 2 shows the stacked FTIR spectra of the modified abaca fibers, as well as that of the unmodified abaca fiber (control). There exists a peak at $3450 \mathrm{~cm}^{-1}$ corresponding to hydroxyl stretching in the spectra of all abaca samples, which is linked to the -OH groups in the cellulose component of the abaca fibers. For the modified abaca fibers, unique peaks are observed at 1080 $\mathrm{cm}^{-1}$ (Si-O-Si) and at $1260-1200 \mathrm{~cm}^{-1}$ (Si-O-C), which are characteristic of the silicon bond vibrations, as reported elsewhere. ${ }^{30-32}$ These peaks are absent in the spectrum of the unmodified abaca. The difference between the FTIR spectra of the organotrialkoxysilane-modified abaca fibers and that of unmodified abaca has given strong evidence that the surface modification procedure used in this work was successful in 
altering the structure of the abaca fibers. The presence of such peaks supports the successful silylation, and therefore, the chemical modification of the abaca fibers.

In the works of Abdelmouleh and coresearchers $(2003)^{33}$ and Rutter and Hutton-Prager (2018), ${ }^{34}$ different silane coupling agents were<smiles>C=C(C)C(=O)OCCC[Si](C)(OC)OC</smiles>

3-(trimethoxysilyl) propyl methacrylate (TMPS) utilized to surface modify cellulosic materials. The silane treatment of the fibers, followed by a heat treatment, resulted in the adsorption of the silanes onto the cellulose surfaces; the chemical bonding of the coupling agents onto the cellulose was confirmed by FTIR spectroscopy.

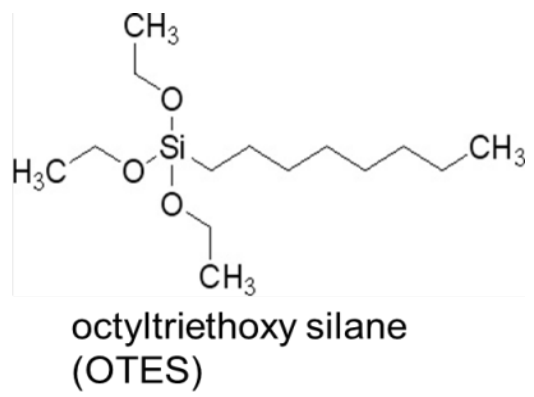

Figure 1: Chemical structure of the organotrialkoxysilane coupling agents used in the study to chemically modify abaca fibers

Some of the $-\mathrm{OH}$ groups of the cellulose substrates were shown to react and formed Si-O$\mathrm{Si}$ and $\mathrm{Si}-\mathrm{O}-\mathrm{C}$ peaks, ensuring successful grafting. The silane modified fibers were shown to exhibit higher contact angles than the unmodified cellulose sample, indicating that the hydrophilicity of the cellulose fibers can be significantly decreased through silylation.

\section{Surface hydrophobicity of modified abaca fibers}

One of the common ways and a fast, practical tool to characterize surface wettability is contact angle measurement. Wettability or the wetting phenomenon refers to the study of how a liquid dropped on a substrate spreads out. The contact angle reflects the hydrophobic or hydrophilic behavior of a material - in most cases, it is deemed to be connected to different surface properties, such as surface porosity, roughness, heterogeneity, etc. ${ }^{35-37}$ The value of the static contact angle made by a liquid droplet deposited on a fiber surface is shown in Figure 3. Since the static contact angle of the water droplet is greater than $90^{\circ}$, this suggests that the affinity between water and the fiber is low; hence the fiber surface is hydrophobic.

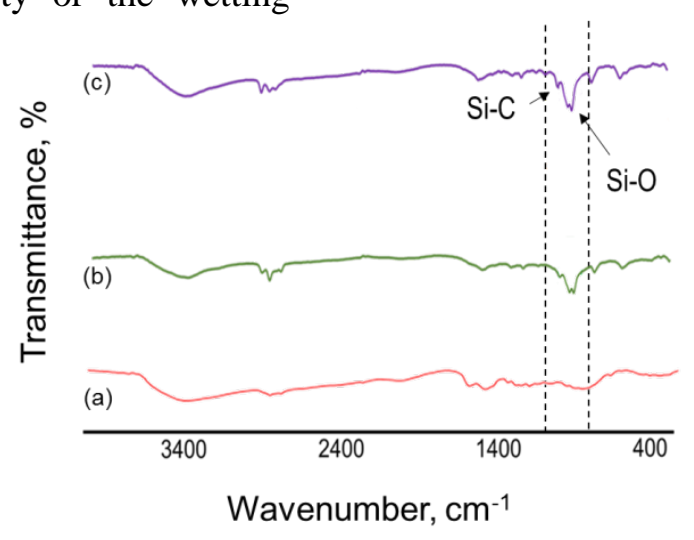

Figure 2: Fourier transform infrared (FTIR) spectra of untreated abaca (a); modified abaca treated with 3(trimethoxysilyl)propyl methacrylate silane (TMPS) (b); and modified abaca treated with octyltriethoxy silane (OTES) (c) 


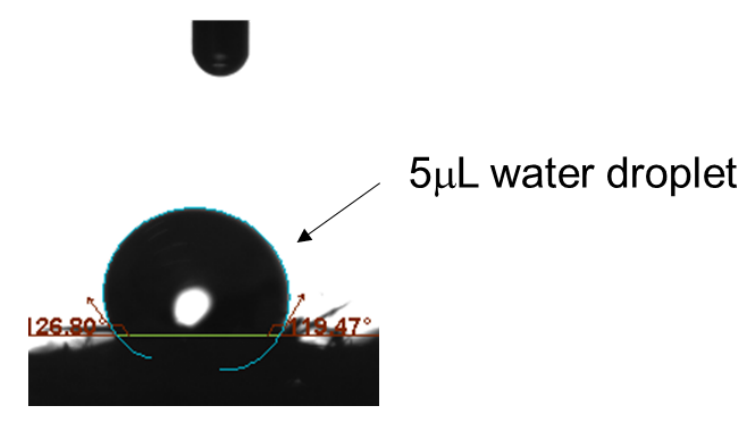

Abaca fiber

Figure 3: Image of a water droplet applied on the abaca fiber sample for contact angle measurement

Both modification treatments utilizing organotrialkoxysilane agents resulted in modified abaca fibers exhibiting higher water contact angles, compared to unmodified abaca fibers. OTES silane agent modified abaca to exhibit an average contact angle of $109.7 \pm 2.7^{\circ}$, while the fiber treated with TMPS showed an average of $103.4 \pm 2.3^{\circ}$. Meanwhile, the water contact angle of the untreated abaca was $64.8 \pm 2.6^{\circ}$. OTESmodified abaca gave higher contact angle values than TMPS-modified fibers, due to its longer alkyl chain. ${ }^{38}$ The higher contact angle values exhibited by the silane-modified abaca fibers compared to those of untreated abaca fibers, as well as the successful chemical modification of these fibers, as confirmed by the FTIR spectroscopic measurements, demonstrated that the hydrophobic modification of abaca fibers by the organotrialkoxysilane coupling agents has been achieved.

In the work of Schramm and Amann (2019), ${ }^{39}$ various trialkoxysilane modifying agents were used in combination with some polymers to surface modify cotton fabrics. After successful silylation was confirmed, the physico-mechanical properties of the silane-modified cotton materials were assessed. Along with increased hydrophobicity, other characteristics, including dry crease recovery (the ability of cotton to recover from wrinkling) and stiffness, were improved in the modified cotton materials. This modification method can, therefore, bring numerous advantages, making the fibers suitable for diverse applications. Also, the modification treatments utilizing organotrialkoxysilane agents

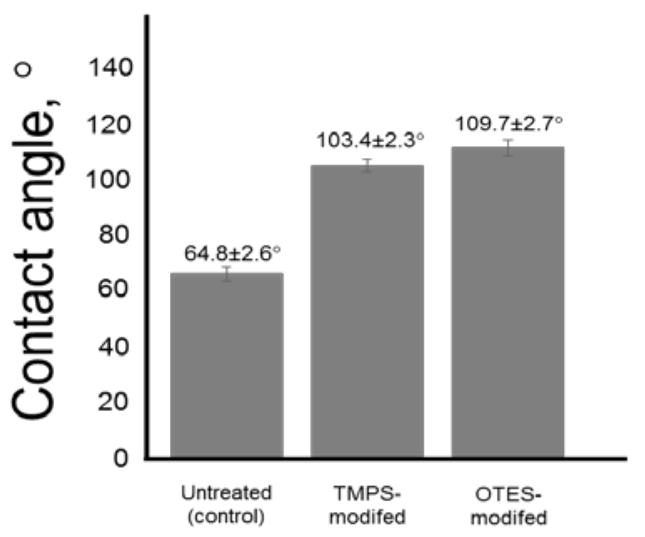

\section{Abaca fibers}

Figure 4: Contact angle of untreated abaca, modified abaca treated with 3-(trimethoxysilyl)propyl methacrylate silane (TMPS); and modified abaca treated with octyltriethoxy silane (OTES)

have been demonstrated efficient in addressing the issue of inherent hydrophilicity in abaca fibers, which prevents their use as filler for polymer composite preparation. Hydrophobized abaca fibers can prevent high moisture absorption, which usually causes poor fiber dispersion and insufficient fiber-matrix interfacial adhesion in natural fiber reinforced polymer composites.

\section{CONCLUSION}

This short communication reports on the successful modification of abaca fibers using two organotrialkoxysilane coupling agents: 3(trimethoxysilyl) propyl methacrylate (TMPS) and octyl triethoxysilane (OTES). The treatment resulted in hydrophobized abaca fibers, as confirmed by the higher water contact angles recorded for the fibers modified by OTES $\left(109.7 \pm 2.7^{\circ}\right)$ and TMPS $\left(103.4 \pm 2.3^{\circ}\right)$, respectively, compared to that of untreated abaca $\left(64.8 \pm 2.6^{\circ}\right)$. In addition, FTIR spectroscopic measurements confirmed the successful chemical bonding of the organotrialkoxysilane agents onto the cellulose structure of the abaca fibers.

\section{REFERENCES}

1 A. K. Bledzki, A. Jaszkiewicz and D. Scherzer, Compos. A: Appl. Sci., 40, 404 (2009), https://doi.org/10.1016/j.compositesa.2009.01.002

2 A. K. Bledzki, A. A. Mamun and O. Faruk, Express Polym. Lett., 1, 755 (2007), https://doi.org/10.3144/expresspolymlett.2007.104

3 M. Cai, H. Takagi, A. N. Nakagaito, Y. Li and G. I. N. Waterhouse, Compos. A: Appl. Sci., 90, 589 (2016), https://doi.org/10.1016/j.compositesa.2016.08.025

4 J. Gironès, J. P. Lopez, F. Vilaseca, R. Bayer, P. J. 
Herrera-Franco et al., Compos. Sci. Technol., 71, 122 (2011), https://doi.org/10.1016/j.compscitech.2010.10.012

5 P. Ramadevi, D. Sampathkumar, C. V. Srinivasa and B. Bennehalli, BioResources, 7, 3515 (2012), https://ojs.cnr.ncsu.edu/index.php/BioRes/article/view/ BioRes_07_3_3515_Punyamurthy_SSB_Alkali_Absor ption_Abaca_Fiber/1614

M. Shibata, K. Ozawa, N. Teramoto, R. Yosomiya and H. Takeishi, Macromol. Mater. Eng., 288, 35 (2003), https://doi.org/10.1002/mame.200290031

N. Teramoto, K. Urata, K. Ozawa and M. Shibata, Polym. Degrad. Stabil., 86, 401 (2004), https://doi.org/10.1016/j.polymdegradstab.2004.04.026 8 A. G. Lalusin and M. L. H. Villavicencio, in "Industrial Crops: Breeding for Bioenergy and Bioproducts”, edited by V. M. V. Cruz and D. A. Dierig, New York, Springer, 2015, pp. 265-289

9 W. Shahri, I. Tahir and B. Ahad, in "Biomass and Bioenergy”, edited by K. Hakeem, M. Jawaid and U. Rashid, Springer, 2014, pp. 47-61, https://doi.org/10.1007/978-3-319-07641-6_3

10 J. E. Spencer, Econ. Bot., 7, 195 (1953), https://doi.org/10.1007/BF02984947

11 K. Vijayalaksmi, C. Y. K. Neeraja, A. Kavitha and J. Hayavadana, Trans. Eng. Sci., 2, 16 (2014)

12 S. W. Saragih, R. Lubis, B. Wirjosentono and Eddyanto, AIP Conf. Procs., 2049, 020058 (2018), https://doi.org/10.1063/1.5082463

${ }^{13}$ K. Liu, H. Takagi and Z. Yang, Compos. A: Appl. Sci., 45, 14 (2013), https://doi.org/10.1016/j.compositesa.2012.09.006

14 B. Madsen and E. K. Gamstedt, Adv. Mater. Sci. Eng., 2, $16 \quad$ (2013), https://doi.org/10.1155/2013/564346

15 A. K. Sinha, H. K. Narang and S. Bhattacharya, Mater. Today Procs., 5, 7284 (2018), https://doi.org/10.1016/j.matpr.2017.11.396

16 M. Tolinski, Plast. Eng., 62, 18 (2006)

17 A. K. Bledzki, O. Faruk and V. E. Sperber, Macromol. Mater. Eng., 291, 449 (2006), https://doi.org/10.1002/mame.200600113

18 F. Corrales, F. Vilaseca, M. Llop, J. Gironès, J. A. Méndez et al., J. Hazard. Mater., 144, 730 (2007), https://doi.org/10.1016/j.jhazmat.2007.01.103

19 R. Gauthier, C. Joly, A. C. Coupas, H. Gauthier and M. Escoubes, Polym. Compos., 19, 287 (1998), https://doi.org/10.1002/pc.10102

20 A. K. Mohanty, M. Misra and L. T. Drzal, Compos. Interface., $\quad \mathbf{8}, 313 \quad$ (2001), https://doi.org/10.1163/156855401753255422

21 M. M. Ruiz, J. Y. Cavaillé, A. Dufresne, C. Graillat and J. F. Gérard, Macromol. Symp., 169, 211 (2001), https://doi.org/10.1002/1521-

3900(200105)169:1<211::AID-MASY211>3.0.CO;2$\mathrm{H}$

22 S. Tragoonwichian, N. Yanumet and H. Ishida, J. Appl. Polym. Sci., 106, 2925 (2007), https://doi.org/10.1002/app.25797
23 Y. Zhou, M. Fan, L. Chen and J. Zhuang, Compos. B: $\quad$ Eng., $\quad 76, \quad 180$ (2015), https://doi.org/10.1016/j.compositesb.2015.02.028

24 X. Colom, F. Carrillo, F. Nogués F and P. Garriga, Polym. Degrad. Stabil., 80, 543 (2003), https://doi.org/10.1016/S0141-3910(03)00051-X

25 H. S. Mansur, C. M. Sadahira, A. N. Souza and A. A. P. Mansur, Mater. Sci. Eng. C, 28, 539 (2008), https://doi.org/10.1016/j.msec.2007.10.088

26 L. Y. Mwaikambo and M. P. Ansell, J. Appl. Polym. Sci., 84, $2222 \quad$ (2002), https://doi.org/10.1002/app.10460

27 R. F. Mendes, L. M. Mendes, J. E. de Oliveira, H. Savastano Junior, G. Glenn et al., Polym. Eng. Sci., 55, 1273 (2015), https://doi.org/10.1002/pen.24065

28 P. G. Pap, in "Applied Plastics Engineering Handbook”, edited by M. Kutz, Oxford, William Andrew Publishing, 2011, pp. 503-517

29 D. P. Penaloza, D. J. Sandberg, M. V. Giotto and T. A. P. Seery, Polym. Eng. Sci., 55, 2349 (2015), https://doi.org/10.1002/pen.24123

30 D. P. Penaloza and T. A. P. Seery, Mater. Res. Ibero Am. J., 22, e2018019 (2019), https://doi.org/10.1590/1980-5373-MR-2018-0192

31 H. O. Finklea and R. Vithanage, J. Phys. Chem., 86, 3621 (1982), https://doi.org/10.1021/j100215a025

32 J. G. Gwon, S. Y. Lee, G. H. Doh and J. H. Kim, J. Polym. Sci., 116, $3212 \quad$ (2010), https://doi.org/10.1002/app.31746

33 M. Abdelmouleh, S. Boufi, M. N. Belgacem, A. P. Duarte, A. Ben Salah et al., Int. J. Adhes. Adhes., 24, $43 \quad$ (2004), $\quad$ https://doi.org/10.1016/S01437496(03)00099-X

${ }^{34}$ T. Rutter and B. Hutton-Prager, Int. J. Adhes. Adhes., $\quad \mathbf{8 6}, \quad 13$ (2018), https://doi.org/10.1016/j.ijadhadh.2018.07.008

35 J. Drelich, Pol. J. Chem., 71, 525 (1997), http://www.ichf.edu.pl/pjch/pj-1997/pj0597.htm\#525

36 R. E. Johnson Jr. and R. H. Dettre, J. Phys. Chem., 68, 1744 (1964), https://doi.org/10.1021/j100789a012

37 H. Rangwalla, A. D. Schwab, B. Yurdumakan, D. G. Yablon, M. S. Yeganeh et al., Langmuir, 20, 8625 (2004), https://doi.org/10.1021/la049073c

38 T. Ji, C. Ma, L. Brisbin, L. Mu, C. G. Robertson et al., Appl. Surf. Sci., 399, 565 (2017), https://doi.org/10.1016/j.apsusc.2016.11.241

39 C. Schramm and A. Amann, Cellulose Chem. Technol., $\quad 53, \quad 347 \quad$ (2019), https://doi.org/10.35812/CelluloseChemTechnol.2019. 53.35 